\title{
Mind the gap: responding to the global funding crisis in family planning
}

\author{
James N Gribble, ScD, Senior Technical Research Associate, The POLICY Project, The Futures Group International, \\ Washington, DC, USA; Victoria Jennings, $\mathrm{PhD}$, Professor and Director, Institute for Reproductive Health, Georgetown \\ University, Washington, DC, USA; Minna Nikula, MD, MPH, Researcher, National Research and Development Center for \\ Welfare and Health, Helsinki, Finland
}

Correspondence: Dr James N Gribble, The Futures Group International, 1050 17th Street, NW, Suite 1000, Washington, DC 20036, USA.Tel: +1 202775 9680.Fax:+1202-775-9698.E-mail: j.gribble@tfgi.com

(Accepted 6 April 2004)

Journal of Family Planning and Reproductive Health Care 2004; 30(3): 155-157

\begin{abstract}
The widening gap between the cost of meeting family planning needs and the funding available for commodities and programmes is a concern among policymakers and reproductive health professionals. The gap could reach US\$210 million by 2015. Its causes are clear; its solutions are not. While changes in programme method mix and cost shifting could address this gap, an oftenoverlooked alternative is the development and introduction of effective, low-cost methods. The Standard Days Method ${ }^{\mathrm{TM}}$ (SDM) has a first-year failure rate of only 4.8 (correct use) and is acceptable to many women around the world. It is easily integrated into programmes. Many SDM users rely on CycleBeads ${ }^{\mathrm{TM}}$ to help identify the days when pregnancy is likely. Though already meeting couples' needs in many places, the SDM responds in a unique way to needs in settings with high use of traditional methods, high levels of unmet need, and chronic depletion of commodities. The donor gap could have negative consequences, but it also facilitates reassessing family planning programme policies to include other effective, low-cost methods.
\end{abstract}

\footnotetext{
Key message points

- The 'donor gap' is being created by the growing demand for family planning services and funding levels that do not keep pace with the growing need.

- One alternative to alleviating the donor gap is the introduction of low-cost, simple, effective methods of family planning, such as the Standard Days Method (SDM).

- Though meeting the family planning needs of many couples, introducing the SDM is especially important in settings with high reliance on traditional methods, high levels of unmet need for family planning, and chronic depletion of contraceptive commodities.
}

\section{Introduction}

The burgeoning gap between the cost of meeting the growing demand for family planning and the limited funding for contraceptive commodities in developing countries is known as the 'donor gap'; the donors being government development agencies, United Nations organisations, the World Bank and international family planning organisations. Just as riders of the London Underground are warned to 'mind the gap' to avoid falling and hurting themselves, policymakers and the reproductive health community have received a similar warning that insufficient funding for family planning commodities is creating a dangerous situation that could hurt countless women and men around the world. The causes of the donor gap are clear; its solutions are not. This commentary explores possible consequences of the gap, and highlights an often-overlooked alternative.

\section{The donor gap}

Fuelling the donor gap is the growing demand for family planning around the world. One factor affecting demand is the increasing number of people of reproductive age. In 2000, there were an estimated 1.261 billion women between the ages of 15 and 49 years in developing countries; that number is expected to reach 1.548 billion by $2015 .^{1}$ These additional 287 million women - almost $23 \%$ more than in 2000 - will place a heavy burden on family planning programmes, even if contraceptive prevalence does not increase. A second factor affecting the demand for commodities is growing contraceptive prevalence. In 2000, prevalence among women in acknowledged relationships (union living) in developing countries was estimated at $59.8 \%$; by 2015 it is estimated to be $65.4 \% .{ }^{1}$ As a result of the increase in prevalence, coupled with the growth in the number of women of reproductive age, current funding levels will no longer be sufficient to meet family planning needs.

What about the costs of the commodities to meet the growing demand for family planning? Table 1 presents three pricing estimates for contraceptive commodities: Bulatao's 1999 estimates based on United Nations Population Fund (UNFPA) schedules, US Agency for International Development (USAID) prices in 2000 and Saunders' 2001 estimates for UNFPA. ${ }^{2-4}$ The per-unit costs are the basis for estimating the commodity cost ranges for 1 year of method use. For example, if a pack of pills costs between $\$ 0.175$ and $\$ 0.287$ then 15 packs, which is the number used by USAID to calculate one couple-year of protection, would cost between $\$ 2.28$ and $\$ 3.73$. Costs of coitus-dependent methods (condoms and spermicides) are based on Stover and colleagues' finding that people who use those methods have intercourse, on average, 64 times per year, an estimate that is much lower than the $105-120$ units used to measure one couple-year of protection. ${ }^{5}$ If a couple uses vaginal spermicides, an estimate of the annual cost of the commodities would range from $\$ 3.84$ to $\$ 8.00$.

When joining the demand for contraception with the cost of the commodities, the significance of 'the gap' becomes apparent. After the International Conference on Population and Development in 1994, donations increased briefly, reaching $\$ 172$ million in 1996 , but dropped to $\$ 131$ million in 1999. ${ }^{3}$ By 2015, Ross and Bulatao project the cost of commodities to reach approximately $\$ 350$ million, a 155\% increase over the 1997-1999 average donation level of $\$ 147$ million. ${ }^{3}$ They then estimate the size of the gap based on two financing scenarios. In one scenario donor funding increases at $3 \%$ per year from the 2000 level and the gap reaches $\$ 140$ million by 2015 . In the second scenario donor funding for commodities is held constant at the 2000 level (approximately $\$ 140$ million) and the gap reaches \$210 million in 2015. While these scenarios represent hypothetical situations, they illustrate a point on 
Table 1 Costs of contraceptive commodities, estimates from 1999 to 2001

\begin{tabular}{|c|c|c|c|c|c|}
\hline \multirow[t]{2}{*}{ Method } & \multicolumn{3}{|l|}{ Cost/unit (US\$) } & \multirow[t]{2}{*}{ Units needed/year } & \multirow[t]{2}{*}{ Cost/year (US\$) } \\
\hline & UNFPA $(1999)^{2}$ & USAID $(2000)^{3}$ & Saunders $(2001)^{4}$ & & \\
\hline \multicolumn{6}{|l|}{ Short-term methods } \\
\hline Pill & 0.287 & 0.217 & 0.175 & 15 packs & $2.28-3.73$ \\
\hline Injectable & 1.100 & 0.970 & 0.675 & 4 shots & $2.70-4.40$ \\
\hline Condom & 0.026 & 0.066 & 0.025 & 64 units & $1.60-4.22$ \\
\hline Vaginal spermicides & 0.099 & 0.125 & 0.060 & 64 units & $3.84-8.00$ \\
\hline \multicolumn{6}{|l|}{ Long-term methods } \\
\hline Norplant ${ }^{\circledR}$ & NA & 23.80 & 23.00 & & $6.57-6.80$ \\
\hline Female sterilisation & 10.64 & NA & NA & & 1.20 \\
\hline Male sterilisation & 5.92 & NA & NA & & 0.67 \\
\hline IUD & 1.65 & 1.45 & NA & & $0.41-0.47$ \\
\hline
\end{tabular}

Cost data sources: Bulatao $(1999)^{2}$, Ross and Bulatao $(2001)^{3}$ and Saunders $(2001)^{4}$. Condom and vaginal spermicide costs/year based on 64 acts of intercourse per year. Long-term methods cost/year based on couple-years of protection (CYP) (i.e. sufficient commodity to provide contraception for one couple for 1 year) factor published by Stover et al. (2000) ${ }^{5}$. NORPLANT based on 3.5 CYP, sterilisation based on 8.9 CYP and IUD based on 3.5 CYP.

IUD, intrauterine device; NA, not available; USAID, US Agency for International Development.

which everyone is in agreement: donor funding for contraceptive supplies is not keeping pace with the increasing demand for family planning.

\section{Solutions to the donor gap}

If the donor gap continues to grow and huge shortfalls in funding for commodities become a reality, what can programmes do to minimise the adverse effects of the situation? Options could include changing donor levels and restrictions; sharing and shifting costs; and introducing alternative, less costly methods.

The most straightforward option involves donors. Raising donor levels and easing restrictions could enable their contributions to have a greater impact on responding to growing needs. However, neither change seems likely under current economic and political conditions. Given that the gap represents as much as $150 \%$ of current donor levels, it is not likely that future donations alone will be able to close the gap.

Cost-sharing, which is frequently discussed in the context of contraceptive security initiatives, is another possibility for maintaining current levels of programme effort. ${ }^{6}$ In that scenario the government and public are called upon to shoulder a greater share of the costs of commodities. One option is for those governments to pass on the additional costs through user fees in the public sector. In some countries this option could be feasible and represents the goal of many health sector reforms. Market segmentation would help identify those individuals most in need of subsidised contraceptives, and require others to pay for family planning. Studies have found that a sizeable percentage of women relying on subsidised pills from the public sector could, in fact, afford to pay for them. ${ }^{7,8}$ Programmes to stimulate the commercial sector could make it a more viable source for family planning. An alternative cost-sharing approach is for communities to use mechanisms such as user fees, revolving funds and insurance programmes as a way to finance family planning commodities and services.

Rather than cost-share, governments could cost-shift by removing some of the more expensive methods from the public sector programme mix. For example, the cost per year of implants and spermicides is much higher than other methods, and in a critical situation the decision might be made to curtail the availability of these methods, at least in the subsidised sector. Along the same line, governments could shift to an emphasis on long-term methods, which would ultimately improve programme cost-effectiveness. Such decisions would drastically reduce the number of choices available to women and men, particularly those methods that contribute to child spacing. In spite of the negative implications for informed choice and quality of care, these options need to be considered as possible courses of action in response to the donor gap.

A more positive alternative is the development and introduction of new, low-cost methods. In a recent workshop on family planning programmes in the $21 \mathrm{st}$ century, cost was cited as the leading factor limiting the availability of long-term hormonal contraceptives, which represent many of the technologies currently being developed. 9 Given the projected donor gap, high-cost methods will place an excessive financial burden on already depleted programmes. Perhaps low-cost methods need to be given greater attention.

A cost-effective alternative: the Standard Days Method A new method that is being introduced into programmes is a fertility awareness-based method, the Standard Days $\operatorname{Method}^{\text {TM }}$ (SDM). It identifies a fixed fertile window in the menstrual cycle and helps users to be aware of the days when pregnancy can occur. To prevent pregnancy, the couple avoids unprotected intercourse on Days 8 to 19 of the woman's cycle. Many couples choose to use condoms when they have intercourse during the fertile days. ${ }^{10-12}$ In a multisite efficacy study, the SDM was found to have a first-year failure rate of 4.8 when used correctly, and 12.0 with typical use, comparing favourably to other user-dependent methods, as shown in Table 2.13,14 The method is easily integrated into primary health care programmes, family planning associations, as well as non-health, non-governmental organisations. ${ }^{15}$ Experienced family planning providers can be trained to offer the SDM in as little as a half day.

Table 2 Rates of unintended pregnancies during the first year of typical and correct use of user-dependent family planning methods

\begin{tabular}{llc}
\hline Method & \multicolumn{2}{l}{ Pregnancy rate } \\
\cline { 2 - 3 } & Typical use & Correct use \\
\hline Chance & 85 & 85 \\
Spermicides & 26 & 6 \\
Cervical cap & & 26 \\
$\quad$ Parous women & 40 & 9 \\
$\quad$ Nulliparous women & 20 & \\
Sponge & & 20 \\
$\quad$ Parous women & 40 & 9 \\
$\quad$ Nulliparous women & 20 & 6 \\
Diaphragm & 20 & 3 \\
Condom & & 5 \\
$\quad$ Male & 14 & 5 \\
$\quad$ Female & 21 &
\end{tabular}

Sources: Hatcher et al. (1998) ${ }^{14}$ and Arévalo et al. (2002)13. NB. Pregnancy rates are drawn from studies using different methodologies and may not be directly comparable. 


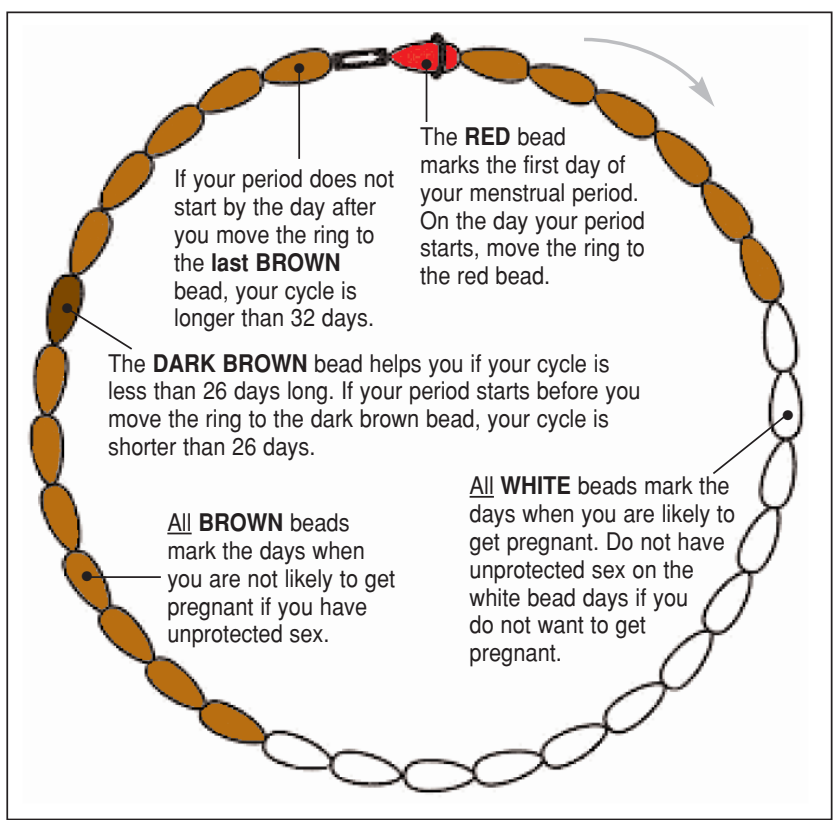

Figure 1 CycleBeads $^{\mathrm{TM}}$ : a tool to help users of the Standard Days Method $^{\mathrm{TM}}$ identify days when pregnancy is likely and where they are in their cycle

SDM users can rely on a color-coded set of beads, known as CycleBeads ${ }^{\mathrm{TM}}$ (Figure 1) to help identify fertile and non-fertile days and monitor cycle length. Each bead represents a day of the cycle, and an 'O' ring is moved each day to the next bead to track the cycle. On brown bead days, the risk of pregnancy is extremely low; on the white bead days, the risk of pregnancy is high. CycleBeads cost approximately $\$ 1.25-\$ 1.50$ to manufacture and get into a distribution system. Their expected product life is more than 2 years, for an annual cost of well under $\$ 0.75$.

Introducing the SDM represents a cost-effective strategy for helping couples achieve their reproductive goals. Given the urgency of the donor gap, the SDM merits consideration in different settings, such as those described below.

1. High use of traditional methods. In Bolivia, for example, where $48 \%$ of contraceptive prevalence is due to use of traditional methods, the SDM would help users of periodic abstinence to identify the days of the cycle when pregnancy is likely to occur. ${ }^{16}$ Similarly, users of withdrawal could also benefit from knowing the days when pregnancy is likely to occur so that on those days they might use barrier methods or avoid intercourse.

2. High unmet need for family planning. In Uttar Pradesh, India, unmet need for family planning is approximately $25 \%$ among married women of reproductive age. ${ }^{17}$ Underlying this unmet need is a contraceptive prevalence of $28.1 \%$, of which more than half is due to female sterilisation. In such a setting many women hesitate to use hormonal contraception for fear that it will make them subfecund or because of prolonged breastfeeding. ${ }^{11}$ The SDM could be a low-cost solution to many women's family planning needs in such settings.

3. Chronic depletion of contraceptive commodities. For a number of reasons, Romania has frequently experienced regular depletion of stocks of contraceptive commodities. ${ }^{18}$ In 1999 , only $27 \%$ of women in union living used modern methods; reliance on withdrawal and sporadic use of condoms contribute to both high method failure and high abortion rates. ${ }^{18,19}$ The SDM could be introduced as both a stopgap measure when supplies are depleted and as an alternative low-cost method into the programme mix.

Further analysis will draw on recent demographic and health survey data and use computer simulations to explore the cost-effectiveness of introducing the SDM into such settings and examine issues related to cost and fertility rates. In the context of shrinking donor support for contraceptive commodities, the SDM provides an economical, effective option that has the potential to respond to both programme and individual needs.

\section{Conclusions}

The warning to the reproductive health community is clear: mind the gap. The growing donor gap could have some significant negative consequences. However, it also offers an opportunity to reassess policies for family planning programmes, including the availability of effective, lowcost methods such as the SDM.

\section{Acknowledgements}

The authors wish to thank John Stover, John Ross, Erin Anastasi and Rebecka Lundgren for thoughtful comments on drafts of this paper.

Statements on funding and competing interests

Funding. This research was funded by the US Agency for International Development Cooperative Agreement \#HRN-A-00-97-00011-00 with Georgetown University Medical Center/Institute for Reproductive Health. Competing interests. None identified.

References

1 United Nations Department of Economic and Social Information and Policy Analysis, Population Division. Levels and Trends of Contraceptive Use as Assessed in 1998. New York, NY. United Nations Department of Economic and Social Information and Policy Analysis, Population Division, 1999

2 Bulatao RA. Reproductive-health Commodity Requirements and Costs in Developing Regions, 1999-2015. New York, NY: United Nations Population Fund, 1999 [cited in Ross and Bulatao, 2001].

3 Ross J, Bulatao R. Contraceptive Projections and the Donor Gap (Meeting the Challenge Series). Rosslyn, VA: John Snow, Inc., 2001.

4 Saunders C. Procurement: A Key Element of Supply Security. Meeting the Reproductive Health Challenge: Securing Contraceptives, and Condoms for HIVIAIDS Prevention (Meeting the Challenge Series). Washington, DC: Population Action International, 2001.

5 Stover J, Bertrand J, Shelton J. Empirically based conversion factors for calculating couple-years of protection. Eval Rev 2000; 24: 3-46.

6 Fort C. Financing Contraceptive Supplies in Developing Countries: Summary of Issues, Options, and Experiences (Meeting the Challenge Series). Rosslyn, VA: John Snow, Inc., 2001.

7 Bulatao RA. What Influences the Private Provision of Contraceptives? Commercial Market Strategies Technical Paper Series No. 2. Washington, DC: The Futures Group International, 2002.

8 Foreit KG. Broadening the Commercial Sector Participation in Reproductive Health. Commercial Market Strategies Project Technical Paper Series No. 3. Washington, DC: The Futures Group International, 2002.

9 Bongaarts J, Johansson E. Future trends in contraceptive prevalence and method mix in the developing world. Stud Fam Plann 2002; 33: 24-36.

10 Gribble J, Velasquez C, Pinto E, et al. Using Condoms Together with Four Methods of Family Planning (Institute Working Paper). Washington, DC: Institute for Reproductive Health/Georgetown University, 2003.

11 Dosajh U, Sood B, Lundgren R. Incorporating the Standard Days Method into CASP Reproductive Health and Sustainability Project, Final Report. New Delhi, India: TNS MODE, 2003.

12 Pavon S, Velasquez C. Introducing the Standard Days Method of Family Planning into Existing Multi-method and Natural Method Family Planning Programs in Honduras, Final Report. Tegucigalpa, Honduras: ASHONPLAFA, 2003.

13 Arévalo M, Jennings V, Sinai I. Efficacy of a new method of family planning: the Standard Days Method. Contraception 2002; 65: 333-338.

14 Hatcher R, Trussell J, Stewart F, et al (eds) Contraceptive Technology (17th edn). New York, NY: Ardent Media, Inc., 1998.

15 Gribble J. The Standard Days Method of family planning: a response to Cairo. Int Fam Plann Perspect 2003; 29: 188-191.

16 Ministerio de Hacienda, Instituto Nacional de Estadística de la República de Bolivia. Programa DHS. Encuesta Nacional de Demográfíca y Salud. Calvert, MD: Demographic and Health Surveys/Macro International Inc., 1998.

17 India Institute for Population Sciences (IIPS) and ORC Macro. National Family Health Survey (NFHS-2), India, 1998-1999. Uttar Pradesh, Mumbai, India: IIPS, 2001.

18 Dayaratna V, Zosa-Feranil I, Stanescu A, et al. Barriers to Implementing Contraceptive Security Policies in Romania. Washington, DC: The Futures Group International, 2002

19 Serbanescu F, Morris L, Marin M (eds). Reproductive Health Survey Romania, 1999. Atlanta, GA: Centers for Disease Control and Prevention, 2001. 